\title{
Disciplina nos mínimos detalhes: Análise dos processos minimalistas na música Discipline (1981) do grupo King Crimson
}

"Discipline" in the minimal details: Analisys of minimalists process in the King Crimson's Discipline (1981)

por Daniel Ribeiro Medeiros

\section{RESUMO}

Este artigo apresenta uma análise da música Discipine, faixa título do LP do grupo King Crimson. Mais especificamente, mostraremos como são abordadas as técnicas minimalistas de defasagem (phasing) e processo aditivo/subtrativo linear. Para fins de contextualização, abordaremos, em linhas gerais, aspectos referentes ao Rock Progressivo (gênero no qual king Crimson se insere), um breve histórico da banda e a relação cultural entre minimalismo e rock progressivo. Após, serão tratadas as técnicas de defasagem (phasing) e processo aditivo/subtrativo linear, bem como a análise dos módulos onde ocorrem tais técnicas na música Discipline.

Palavras-chave King Crimson; Rock Progressivo; Minimalismo; Análise

\section{ABSTRACT}

This paper presents a musical analysis of Discipline, eponymous track of the King Crimson's LP. More specifically, we'll show how the minimalists techniques of phasing and aditive/subtractive linear process are used. For purposes of contextualization, will be adressed general aspects of Progressive Rock, a brief history of the band and the cultural relation among minimalism and progressive rock. Also, we'll be consider the minimalists techniques here mentioned and we will analyze the modules where occur these techniques in Discipline track.

Keywords King Crimson; Progressive Rock; Minimalism; Analisys 


\section{Rock Progressivo: apontamentos gerais}

Nascido como parte do movimento da contracultura (counter-culture)' britânica de meados a fins da década de sessenta, o Rock Progressivo caracteriza-se como uma maneira de se fazer música que combina formas e elementos advindos basicamente de gêneros como o erudito, jazz e rock (SHUKER, 2005, p.209-210). Para muitos, tem como ponto de partida o album Sergeant Pepper's Lonely Hearts Club Band (1967) dos Beatles. Conforme Edward Macan, este álbum marca de forma clara o nascimento de uma música que fundiu elementos e formas como o rock, música erudita, jazz, folk e música indiana, trazendo "uma crença de que essa nova música poderia ao mesmo tempo ser criativa e popular" (MACAN, 1997, p.15, TRADUÇÃo NOSSA). Portanto, essa nova música, que mais tarde se tornaria conhecida como Rock Progressivo, foi marcada, acima de tudo, pela sua diversidade e ecletismo (MOORE apud SHUKER, 2005, p.210).

Suas formas paradigmáticas e bem caracterizadas musicalmente começaram a surgir no início dos anos setenta, através do trabalho de grupos como Nice, Yes, King Crimson, ELP (Emerson, Lake O Palmer), Pink Floyd, Genesis, dentre tantos outros. A maioria dos músicos destas bandas teve formação musical através da tradição de ensino da música erudita de base européia. Este aspecto, juntamente com o fato de que a preocupação musical residia em elementos como o timbre, textura, dentre outros, evidencia, em grande medida, a imitação consciente de protótipos da música erudita, muitas vezes emprestados de formas sinfônicas (MACAN apud SHUKER, 2005, p.210). Um exemplo musical bastante citado pela literatura especializada destaca a música A Whiter Shade of Pale (1967), da banda Procol Harum, na qual o arranjo do órgão (principalmente a progressão harmônica) foi baseado na Suite $n^{\circ} 3$, em Ré maior, de Johann Sebastian Bach (SHUKER, 2005, p.209-210).

0 fato de várias bandas e músicos ligados ao Rock Progressivo pesquisarem variados aspectos relacionados ao som, estruturas das canções, sistemas de afinação não usuais, dissonâncias, elementos e instrumentos musicais de outras culturas, além de trabalharem com a combinação de vários gêneros (erudito, jazz, etc), confere também um caráter experimental, de vanguarda (avant-garde), pois acabaram quebrando com tradições, estilos e convenções estabelecidas à época (SHUKER, 2005, p.18-19). É dentro deste contexto musical que surge o grupo King Crimson.

1 Para maiores detalhes sobre a relação entre música (rock, dentre tantos outros gêneros) e contracultura, recomendamos, como leitura inicial, o verbete counter-culture; underground em Popular Music: the Key concepts (1999), de Roy Shuker. 


\section{King Crimson: considerações gerais}

Formado em $1969^{2}$, King Crimson tornou-se uma das bandas mais influentes do Rock Progressivo britânico na década de 1970. Seu primeiro álbum, In the Court of the Crimson King (1969), tornou-se o primeiro LP (long playing record) clássico do gênero. Conforme Andrew Keeling, após este álbum, o rock nunca mais foi o mesmo:

King Crimson definiu os padrões de execução, gravação e letras para as bandas de Rock Progressivo subseqüentes. Por exemplo, Pawn Hearts do Van der Graaf Generator, Foxtrot do Genesis, Time and Word do Yes e o álbum epônimo do Renaissance (o qual também tem cinco canções), foram todos influenciados por In the Court of the Crimson King. Mesmo Deep Purple (o riff de Into the Fire, do Deep Purple in Rock, é uma transformação do riff ritornello de Schizoid Man) e Black Sabbath (Paranoid) mostram a influência do king Crimson (KEELING, 2010, p.70, TRADUÇÃO NOSSA).

Keeling (2010) ainda destaca a natureza poli-estilística do álbum, caracterizada pelas referências ao jazz, rock, folk, música erudita e música para filmes, uma forma de se fazer música que ia de encontro ao pensamento do establishment cultural da época, demonstrando a plasticidade e o ecletismo que a música popular - e mais precisamente o Rock Progressivo - viria experimentar (KEELING, 2010, p.71).

John Covach, no verbete King Crimson do New Grove Dictionary of Music and Musicans (2001), também destaca características gerais de In the Court of the Crimson king (1969). Para ele, já neste primeiro disco, são apresentadas músicas que misturam freqüentemente passagens agressivas e angulares, métricas incomuns para os padrões do rock, seções com caráter lírico e pastoral, dentre outras características (COVACH, 2001, p.609).

Alguns fatores levaram o grupo a passar por formações diversas, o que de certa forma pode ter contribuído para as variadas mudanças de perspectivas estilísticas do grupo. Este aspecto reflete-se de maneira bem clara no livro Robert Fripp ${ }^{3}$ : from Crimson King to Crafty Master (1990), de Eric Tamm. 0 autor passa a considerar a banda, historicamente e esteticamente, através de suas formações: King Crimson I, II, III e IV (TAMM, 1990). E é dentro da formação KC IV que o disco Discipline (1981) no qual encontra-se a faixa de mesmo nome e que aqui será analisada - se insere.

Após a dissolução do KC III, no ano de 1974, a banda passou a ser formada pelos músicos Bill Bruford (bateria), Tony Levin (baixo, Chapman Stick ${ }^{4}$ ) e Andrew Belew

2 Em sua primeira formação, a banda contava com os seguintes músicos: Robert Fripp (1946; guitarra e líder da banda), Greg Lake (1948; baixo e vocal), Ian McDonald (1946; teclados e flauta), Michael Giles (bateria) and Peter Sinfield (letras).

3 Guitarrista e líder do King Crimson.

4 Instrumento elétrico com cinco cordas agudas, tocadas com a mão direita, e cinco cordas graves, tocadas pela mão esquerda. A técnica de execução envolve basicamente a digitação dos 
(guitarra e vocal), além de Robert Fripp (guitarra). Foram gravados três discos, que para muitos autores, apresentam forte influência do minimalismo norte-americano (COVACH, 2001, p.610): Discipline (1981), Beat (1982), e Three of a Perfect Pair (1984). Tamm (1990) trata-os como uma trilogia, um corpo musical considerado como um todo, o qual apresenta um novo estilo de rock, "quase incomparável em sua sofisticação" (TAMM, 1990, p.115, TRADUÇÃ̃ NOSSA). Esta sofisticação, segundo 0 autor ${ }^{5}$, caracteriza-se, em linhas gerais, através dos seguintes aspectos: o ritmo e o formato instrumental do rock; características da world music; influência do gamelão indonésio e percussão africana; alta tecnologia, principalmente no que tange à utilização de guitarras sintetizadas, efeitos diversos e bateria sintetizada; minimalismo (TAMM, 1990, p.115). Em termos de estruturação musical, ainda destaca:

- métricas complexas, polimetrias;

- ostinatos;

- frases instrumentais sobrepostas de forma não-sincronizada;

- ambigüidade tonal;

- dentre outros.

\section{Minimalismo e Rock Progressivo}

0 movimento minimalista na música surgiu nos Estados Unidos da década de 1960 e teve como principais fundadores compositores como LaMont Young (1935), Terry Riley (1935), Steve Reich (1936) e Philip Glass (1937). Consagrado internacionalmente, este movimento estético, com suas técnicas composicionais específicas, consolidou-se ao longo dos anos, seja através da utilização estrita de suas técnicas ou de adaptações e usos mais livres de seus processos.

As técnicas minimalistas têm se refletido na obra de compositores como Arvo Pärt (1936), Louis Andriessen (1939), Michael Nyman (1944), John Adams (1947) e Michael Torke (1961), assim como em vários gêneros de música popular (new age, world music) (CERV0, 2005, p.44).

0 termo foi cunhado para caracterizar um estilo de composição em que o vocabulário rítmico, melódico e harmônico são intencionalmente simplificados, opondo-se amplamente ao serialismo total, representado principalmente por Pierre Boulez (1925) e Karlheinz Stockhausen (1928-2007), e pela estética da indeterminação, concebida por John Cage (1912-1992) (POTTER, 2001, p.[s/p]).

- dedos sobre as cordas, como se fosse um piano. Maiores informações: http://www.stick.com/.

5 As análises de Tamm (1990) são superficiais, sendo apresentadas somente verbalmente. 
Conforme Cervo (2005), os compositores citados acima (assim como tantos outros) - principalmente aqueles ligados à evolução histórica da música de base cultural européia - representavam o establishment na música, ou seja, representavam o "sistema" de pensamento musical em vigência. 0 minimalismo, então, surge como uma forma alternativa de composição musical, estabelecendo um movimento contrário frente aos valores referentes à música do pós-guerra (CERV0, 2005, p.45-46). Em linhas gerais, a distinção se dá através do seguinte quadro:

\begin{tabular}{|c|c|}
\hline Minimalismo & Serialismo total, indeterminação \\
\hline $\begin{array}{c}\text { Linguagem melódico/harmônica Tonal ou } \\
\text { Modal }\end{array}$ & Atonal \\
\hline Ritmicamente regular e contínuo (periódico) & Ritmo aperiódico e fragmentado \\
\hline Estruturalmente e texturalmente simples & Estruturalmente e texturalmente complexo \\
\hline
\end{tabular}

Tabela 1 - características gerais entre minimalismo e serialismo total e indeterminação.

0 contexto em que surge o movimento minimalista é extremamente favorável no que diz respeito à sua rejeição para com o "sistema". 0 movimento da contracultura californiana (nos anos sessenta) e a cena artística da downtown de Manhattan (1960-70) são ambientes culturais que à época foram importantes para aqueles que desejavam romper com as barreiras artísticas em vigência (POTTER, 2001, p.[s/p]). Cervo (2005) resume de forma bem clara o contexto cultural ${ }^{6}$ em que nasce o minimalismo. Parafraseando Robert Morgan’:

[...] nos anos 50, serialismo e indeterminação eram as duas direções composicionais dominantes. Elas foram seguidas por uma série de novas tendências nos anos 60, dentre as quais destaca-se o Minimalismo. 0 pluralismo radical da cultura contemporânea tornou-se evidente a partir dos anos 60, quando a incessante procura por algo "novo" fez com que movimentos artísticos surgissem quase que de ano em ano. Morgan cita como causas dessa explosão de novas manifestações artísticas a profunda insatisfação da juventude com os valores tradicionais, rebelião contra o que a juventude da época percebia como centralismo monolítico, além

\footnotetext{
6 Não nos estenderemos em aspectos culturais aqui. Na década de 1960 começou uma série de grandes transformações culturais de toda sorte e em todo o mundo. No âmbito musical, 0 ecletismo na música popular é uma marca forte do período. No que diz respeito à relação entre Rock Progressivo e Minimalismo, assim como outros gêneros e estilos, aconselhamos, para 0 momento, a leitura do livro de Edward Macan, Rocking the Classics: English Progressive Rock $\circlearrowright$ the Counterculture (1997).
}

7 MORGAN, Robert. Twentieth-Century Music. New York: Norton, 1991. 
do demasiado elitismo no contexto cultural e político estabelecido. Essa juventude (à qual pertenciam os compositores iniciadores do Minimalismo) explorou uma ampla gama de estilos alternativos de vida que incluíam temas como a emancipação sexual, o interesse pelo misticismo oriental e filosofias não ocidentais, experiências com drogas e principalmente uma forte rejeição aos valores tradicionais do sistema (establishment, ou conjunto dos grupos dominantes dentro de uma sociedade), que era visto como uma força impessoal que vitimava os cidadãos, impedindo-os de exercerem sua liberdade. Morgan também argumenta que as gerações jovens tinham aversão à alta cultura, que era vista como uma cultura em processo de exaustão. No lugar dela, uma contracultura, a qual respondia a uma imensa variedade de interesses sociais e étnicos, foi erguida. A cultura centralizada seria substituída por uma democracia de contraculturas, que coexistiriam em pé de igualdade. Assim, a alta cultura, nos anos 60, começou a perder espaço para a cultura pop. Essa erosão de barreiras entre níveis artísticos estimulou o ecletismo e novas combinações estilísticas (MORGAN apud CERVO, 2005, p.45, GRIFO NOSSO).

Este ambiente, portanto, marcou o enfraquecimento da histórica dicotomia entre música erudita e popular.

Além do próprio contexto cultural, a eletrônica também teve papel importante neste processo. A utilização de instrumentos eletrônicos na música "erudita", como a guitarra elétrica, um instrumento marcadamente vinculado à música popular, especialmente ao rock, assim como o interesse de alguns grupos de música pop pela música de vanguarda (Stockhausen, por exemplo), contribuíram, de certa forma, para que a distinção se tornasse mais frágil (GRIFFITHS, 1987, p.154). Além disso,

In C, peça composta em 1964 por Terry Riley (1935), é um exemplo desse tipo de trabalho na fronteira entre os gêneros. Riley fornece apenas um certo número de fragmentos modais, que os executantes interpretam livremente dentro de um ritmo regular, gerando repetições obsessivas $e$ motivos espontâneos - recursos que seriam imitados tanto na música popular quanto na erudita (GRIFFITHS, 1987, p.154).

Conforme Macan (1997), que também destaca este contexto de limites enfraquecidos em vários aspectos, o público do Rock Progressivo frequentemente era 0 mesmo que ia a concertos de música minimalista. No entanto, destaca surpreso o fato dos dois estilos não terem se interpenetrado de uma forma mais efetiva:

Há passagens isoladas no rock progressivo que carregam uma semalhança quase misteriosa às peças minimalistas contemporâneas. $A$ abertura de 'Lost' (1970), de Van der Graaf Generator, assemelha-se às ativas redes de ostinatos dominadas pelos instrumentos de sopro, frequentemente usadas por Philip Glass, em sua música dos anos 70; os padrões de ostinatos sobrepostos e as métricas assimétricas de 'Infinite Space' (1971) de 
Emerson, Lake $\circlearrowright$ Palmer, sugerem uma versão desacelerada do Octeto (1978) de Steve Reich (MACAN, 1997, p.139, TRADUÇÃO NOSSA, GRIFO NOSSO).

A conexão mais íntima entre minimalismo e rock progressivo começa a aparecer no trabalho desenvolvido por Brian Eno (1948) e Robert Fripp. Os albuns No Pussyfooting (1972) e Evening Star (1975) são considerados como a criação do rock minimalista. No entanto, este trabalho acabou por não influenciar a composição das músicas do King Crimson à esta época, embora Fripp estivesse trabalhando em ambos projetos simultaneamente (MACAN, 1997, p.140). Sobre as técnicas empregadas nos dois albuns mencionados, o autor comenta:

Nestes dois albuns, Eno baseou-se na técnica de tape loop ${ }^{8}$ desenvolvida por Terry Riley e Steve Reich: pequenos fragmentos melódicos e zumbidos (na maioria das vezes tocados por Fripp na guitarra elétrica) são enlaçados ${ }^{9}$ uns sobre os outros continuamente, de modo que mesmo que alguns padrões desapareçam no fundo aural, outros são introduzidos. 0 resultado geral é do mesmo tipo da paisagem que evolui lentamente que é perceptivel na música dos minimalistas (MACAN, 1997, p.140, TRADUÇÃO NOSSA).

No entanto, anos mais tarde, técnicas minimalistas viriam a ser empregadas nas músicas da banda king Crimson. Fripp, juntamente com a nova formação do grupo, desenvolve abordagens próprias sobre técnicas minimalistas em suas músicas. Essas práticas são observáveis no LP Discipline (1981), o qual é destacado por Macan (1997) como um divisor de águas entre o Rock Progressivo clássico, que à época já se apresentava como um gênero enfraquecido em termos de viabilidade comercial frente aos novos valores impostos pela indústria ${ }^{10}$, e 0 pós-progressivo (post- progressive), considerado como a renovação do gênero através de uma influência mais forte do minimalismo, música étnica, dentre outros (MACAN, 1997, p.12).

observa-se, então, que a relação entre o rock progressivo e minimalismo se dá em decorrência de um ambiente cultural multi-facetado, onde o ecletismo se manifesta, principalmente em relação à manifestações que ocorrem no âmbito ou em torno da música popular. Dentro deste contexto mais plural, "multi-cultural", as palavras de David Beard e Kenneth Gloag resumem bem esta idéia no verbete postmodernism:

Muitos estilos musicais diferentes coexistem sem que haja quaisquer conjuntos de valores culturalmente dominantes ou um estilo definitivo. Isso é mais evidente na música popular, que em suas manifestações populares

8 Loop de fita.

9 Looped over.

10 Sobre o declínio do Rock Progressivo frente à indústria da música, recomendamos a leitura de Rocking the Classics: English Progressive Rock $\circlearrowright$ the Counterculture, de Edward Macan. 


\section{As técnicas de defasagem (phasing) e processo aditivo/subtrativo linear (linear additive process) em exemplos extraídos da obra de Steve Reich e Philip Glass}

Conforme dito anteriormente, o foco deste artigo dirige-se à maneira como as técnicas minimalistas de defasagem" (phasing) e processo aditivo/subtrativo linear (linear additive process) são trabalhadas na música Discipline. Para tal, é importante caracterizar tais técnicas, tão importantes na consolidação do minimalismo clássico ${ }^{12}$.

A defasagem é a principal técnica utilizada por Steve Reich em suas obras compostas para fita magnética entre 1965 e 1972: It's Conna Rain (1965) e Come Out (1966). A voz humana é utilizada como material composicional a ser tratado:

Em It's Gonna Rain dois excertos idênticos (pré-gravados) são alinhados em uníssono, e gradualmente um deles é ligeiramente acelerado. Uma vez que o processo é posto em movimento, os dois trechos defasam gradualmente até voltarem ao uníssono novamente no final da obra. No decorrer da peça, essa relação de duas vozes é ampliada para quatro e oito vozes (CERVO, 2005, p.49).

Essa experiência com loops defasados em fitas magnéticas logo foi traduzida para a música instrumental. Em Piano Phase (1967), peça composta para dois pianos ou duas marimbas, um padrão de doze notas é sobreposto. Inicialmente, tal sobreposição é tocada de forma simultânea. Após algumas repetições, um dos instrumentos acelera gradualmante, gerando a defasagem. Quando a segunda semicolcheia no instrumento em que ocorre a defasagem se encontra com a primeira

11 Utiliza-se aqui a tradução proposta por Cervo (2005, p.49), ou seja, o termo defasagem será empregado para designar a técnica de phasing.

12 Minimalismo clássico é aqui entendido da mesma forma como colocada por Cervo (2005) em nota de rodapé: "A expressão Minimalismo "clássico", no contexto deste artigo, refere-se às obras minimalistas compostas entre os anos de 1964 e 1976, as quais se caracterizam pela utilização clara, sistemática e radical de processos composicionais já bem documentados. A partir de 1976, a produção dos compositores minimalistas começou a sofrer mudanças significativas, em obras onde os processos passam a ter importância secundária ou são completamente abandonados. As diferenças entre o Minimalismo "clássico" e essa produção a partir de 1976, que consideramos pósminimalista, é discutida e examinada em detalhe em CERVO (1999)" (CERV0, 2005, p.49). 
semicolcheia do instrumento que mantém a mesma velocidade do padrão (instrumento de referência), ocorrendo um alinhamento métrico entre os instrumentos, 0 "novo" padrão é repetido algumas vezes (CERV0, 2005, p.49-50). 0 processo pode ser representado graficamente da seguinte maneira:

\section{Piano I

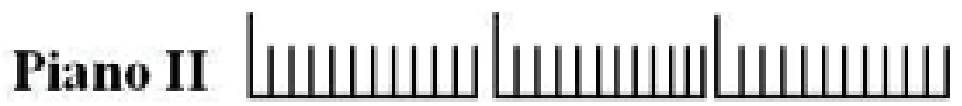

Figura 1 - Processo de defasagem por aceleração em Piano Phase (Reich).

Embora os padrões sejam aqui repetidos incessantemente, há um processo que os coloca em movimento. Conforme Cervo, surgem eventos estáveis, aqueles que ocorrem nos pontos de alinhamento métrico, e os instáveis, aqueles que ocorrem no ato de aceleração do padrão por parte do segundo instrumento (CERVO, 2005, p.51). Para finalizar este processo, o autor destaca:

[...] uma gama ampla de efeitos acústicos e psicoacústicos ocorre, e, embora o processo repita sempre o mesmo material, a obra soa sempre diferente e viva. Cada vez que um alinhamento ocorre, ele soa diferente do precedente, e cada vez que existe uma aceleração ou defasagem, a forma como esta se dá é única (CERVO, 2005, p.51).

Em Discipline, as seções onde ocorrem o processo de defasagem ocorrem da mesma maneira como é trabalhada em Clapping Music (1972) de Steve Reich:

\section{clapping music}

for two performers

steve reich

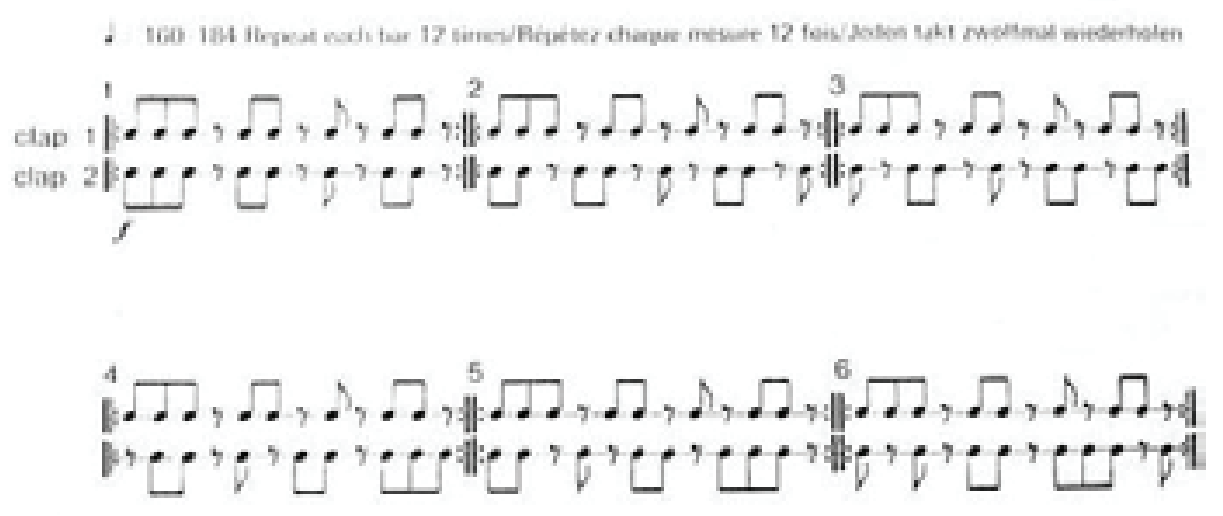

Figura 2 - Primeiros compassos de Clapping Music (Reich). 
Aqui, o processo de defasagem não se dá através de aceleração do padrão, tal como ocorre em Piano Phase (1967). Não há, no momento da troca de fases, uma quebra da simultaneidade do referencial métrico entre os executantes. Pode-se representar o processo da seguinte forma:

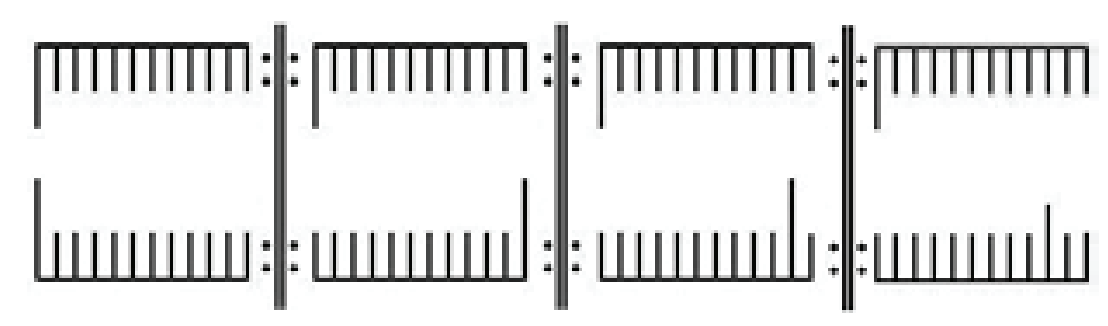

Figura 3 - Processo de defasagem sem aceleração em Clapping Music (Reich).

A técnica de processo aditivo/subtrativo linear caracteriza-se basicamente pela adição ou subtração de elementos constituintes de um padrão. Esta técnica, conforme Cervo, foi trabalhada amplamante por Philip Glass em suas primeiras obras minimalistas (CERVO, 2005, p.52). 0 mesmo autor resume o processo:

[...] se temos um padrão 1-2, após um certo número de repetições adiciona-se mais um elemento 1-2-3, gerando assim um processo gradativo de adição linear. Esse processo pode ser regular com a adição de um número regular de unidades durante o processo de repetição (ex. 1, 1-2, 1-2-3), ou ainda irregular coma adição de um número irregular de unidades (ex. 1, 1-2-3, 1-2-3-4, 1-2-3-4-5-6) durante o processo de repetição (CERVO, 2005, p.52).

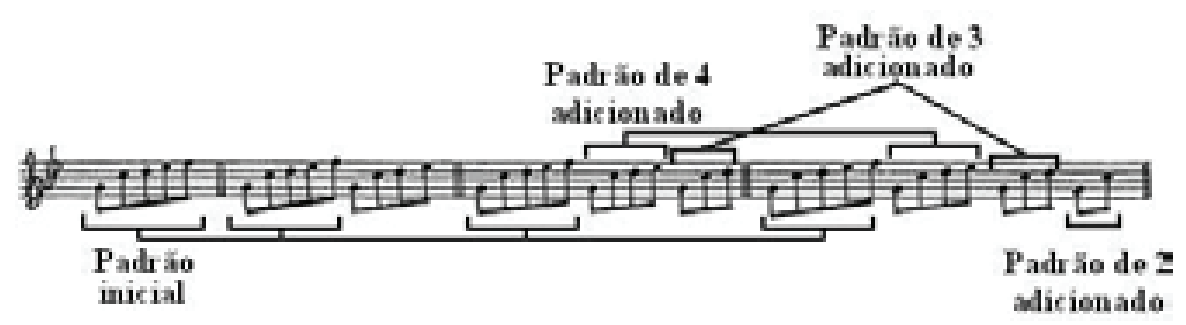

Figura 4 - Primeiros compassos de Two Pages (Glass).

Com o exposto acerca das técnicas de defasagem e processo aditivo/subtrativo linear, tem-se um ponto de partida para a análise de como estas são trabalhadas no arranjo das duas guitarras em Discipline. 


\section{Análise ${ }^{13}$ da música Discipline}

0 LP Discipline compõe-se através das seguintes faixas:

\begin{tabular}{|l|}
\hline 1. Elephant talk $\left(4^{\prime} 47\right)$ \\
\hline 2. Frame by frame $\left(5^{\prime} 08\right)$ \\
\hline 3. Matte kudasai $\left(3^{\prime} 45\right)$ \\
\hline 4. Indiscipline $\left(4^{\prime} 31\right)$ \\
\hline 5. Thela hun ginjeet $\left(6^{\prime} 45\right)$ \\
\hline 6. The sheltering sky $\left(8^{\prime} 22\right)$ \\
\hline 7. Discipline $\left(5^{\prime} 02\right)$ \\
\hline
\end{tabular}

Tabela 2 - Faixas do LP Discipline.

Discipline é uma peça instrumental que apresenta a seguinte instrumentação: duas guitarras, chapman stick e bateria.

Sua organização formal ocorre através da articulação de módulos que se caracterizam pela repetição incessante de padrões motívicos. As variações, em sua grande parte, giram em torno de novas idéias motívicas (quando surgem) que, conseqüentemente, geram novos módulos; ou ocorrem através da transposição harmônico/melódica direta de um mesmo padrão. A tabela abaixo mostra como os módulos estão organizados:

\begin{tabular}{|l|l|l|}
\hline Seções $^{14}$ & Minutagem & Região harmônica \\
\hline Seção A & $0^{\prime}: 00^{\prime \prime}-0^{\prime}: 44^{\prime \prime}$ & Lá menor \\
\hline Seção B & $0^{\prime}: 45^{\prime \prime}-01^{\prime}: 02^{\prime \prime}$ & $\begin{array}{l}\text { Ambigüidade harmônica'5 } \text { menor; Mi maior menor; Dó\# } \\
\text { menor }\end{array}$ \\
\hline Seção A' & $01^{\prime}: 03^{\prime \prime}-01^{\prime}: 24^{\prime \prime}$ & Lá menor (com aplicação de defasagem) \\
\hline Seção B & $01^{\prime}: 25^{\prime \prime}-01^{\prime}: 42^{\prime \prime}$ & Sol\# menor \\
\hline Seção C & $01^{\prime}: 43^{\prime \prime}-02^{\prime}: 16^{\prime \prime}$ & Fá\# menor (com aplicação de defasagem) \\
\hline
\end{tabular}

13 A análise estará focada no arranjo das guitarras. É através destes instrumentos que se dá o processo de defasagem (phasing).

14 Em decorrência da especificidade dos processos composicionais adotados em Discipline, considera-se aqui as variantes das seções A, C e D $\left(A^{\prime} ; C^{\prime}, C^{\prime \prime}, C^{\prime \prime \prime}\right.$ e $\left.C^{\prime \prime \prime \prime} ; D^{\prime}\right)$ como subseções. Interpreta-se dessa maneira pela reiteração dos mesmos padrões motívicos. Os módulos variantes, que aqui são designadas por ', ", “" e “'”, ocorrem tanto por leves modificações dos motivos, transposições e variações nos tratamentos do processo de defasagem.

15 Nesta Seção, a ambigüidade se dá em decorrência da ênfase em certas notas que cada guitarra e o stick chapman apresentam. Uma guitarra apresenta um padrão que destaca a sonoridade através da escala de Sol\# menor (pentatônica); a outra guitarra, de Dó\# menor (pentatônica); e o stick chapman, de Mi maior. 


\begin{tabular}{|l|l|l|}
\hline Seção D & $02^{\prime}: 17^{\prime \prime}-02^{\prime}: 28^{\prime \prime}$ & Lá menor \\
\hline Seção D' & $02^{\prime}: 29^{\prime \prime}-02^{\prime}: 50^{\prime \prime}$ & $\begin{array}{l}\text { Dó menor (transposição do mesmo padrão } \\
\text { motívico de D) }\end{array}$ \\
\hline Seção C' & $02^{\prime}: 51^{\prime \prime}-03^{\prime}: 24^{\prime \prime}$ & Dó menor (com aplicação de defasagem) \\
\hline Seção C" & $03^{\prime}: 25^{\prime \prime}-04^{\prime}: 09^{\prime \prime}$ & $\begin{array}{l}\text { Dó\# menor (com aplicação de defasagem e } \\
\text { variação do padrão motívico de C') }\end{array}$ \\
\hline Seção C'"' & $04^{\prime}: 10^{\prime \prime}-04^{\prime}: 35^{\prime \prime}$ & Mi menor (com aplicação de defasagem) \\
\hline Seção C'"' & $04^{\prime}: 36^{\prime \prime}-05^{\prime}: 02^{\prime \prime}$ & Fá\# menor \\
\hline
\end{tabular}

Tabela 3 - Organização formal de Discipline.

É interessante notar aqui que praticamente todos os módulos baseam-se na sonoridade das escala pentatônica menor, conferindo uma sonoridade característica à peça.

Os pocessos minimalistas de defasagem e processo aditivo/subtrativo linear ${ }^{16}$ ocorrem nas seções A', C, C', C'”, C'"' e C'"'’. A maneira como essas técnicas foram abordadas chama atenção: o processo de defasagem ocorre em decorrência do processo subtrativo linear. Ou seja, a defasagem não surge através dos métodos destacados mais acima (Piano Phase e Clapping Music de Steve Reich), mas sim, como conseqüência de uma subtração dos padrões referenciais. É dessa maneira que 0 trabalho do King Crimson apropria-se destas técnicas minimalistas na faixa Discipline.

No início da Seção $A^{\prime}$ o mesmo padrão $5(3+2)$ é inicialmente tocado por ambas guitarras:

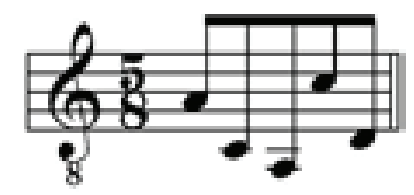

Figura 5 - Padrão de $5(3+2)$ que inicia a Seção $A^{\prime}$.

A guitarra right, para iniciar o processo de defasagem, subtrai a última nota do padrão, tranformando-o em $4(3+1)$ :

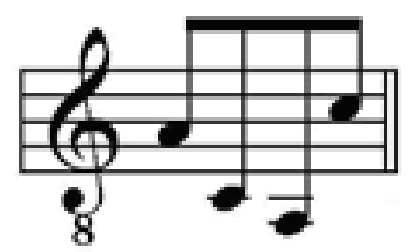

Figura 6 - Padrão de $5(3+2)$ é transformado para $4(3+1)$.

16 No caso de Discipline, trata-se mais especificamente de ser subtrativo. 
Este procedimento é colocado em ação pelas guitarras sob uma mesma perspectiva métrica, tal como ocorre em Clapping Music ${ }^{17}$ (Reich).

A Seção $A^{\prime}$ está estruturada da seguinte maneira: a guitarra right articula os padrões $5(3+2)$ e $4(3+1)$, fazendo com que em determinado ponto o padrão $5(3+2)$ coincida em ambas guitarras, finalizando o processo de defasagem:

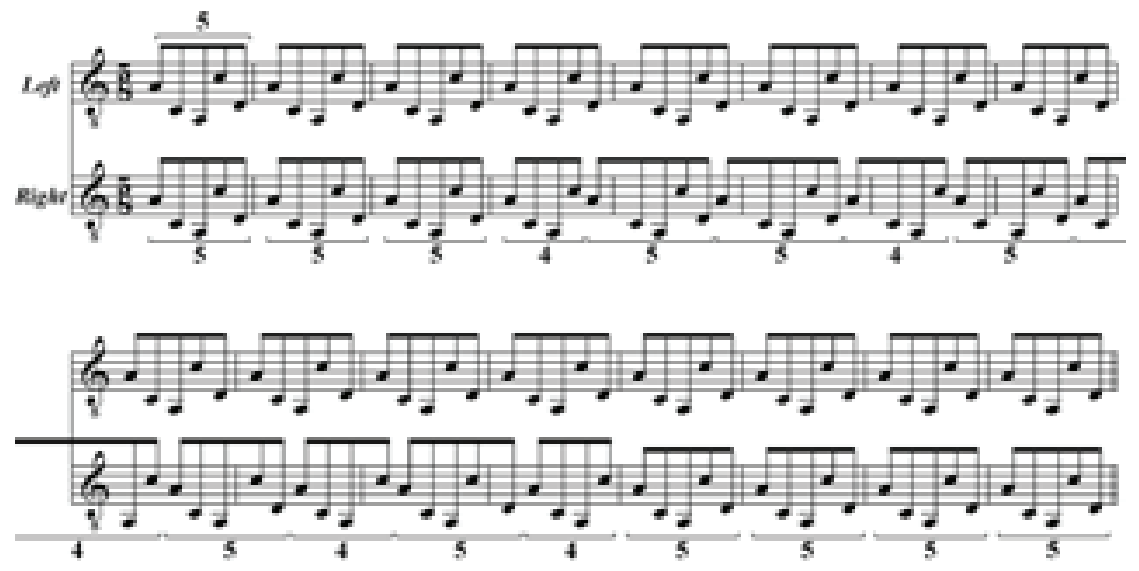

Figura 7 - Seção $A^{\prime}$.

0 efeito caleidoscópico pode ser compreendido das seguintes maneiras (Fig.8 e Fi.9):

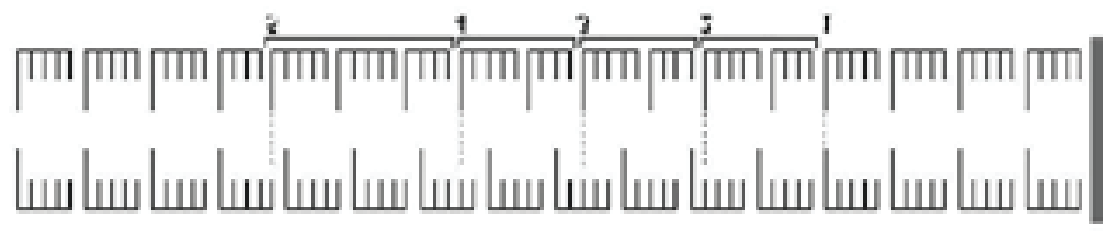

Figura 8 - Processo de defasagem na Seção $A^{\prime}$.

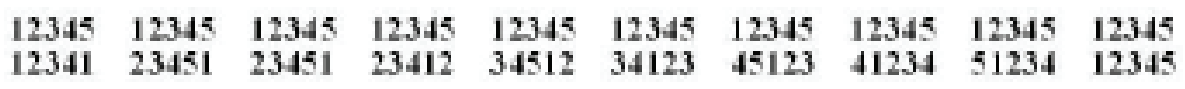

Figura 9 - Relacionamento entre as unidades numéricas da Seção A'.

0 mesmo método que ocorre na Seção A' ocorre na Seção C: defasagem gerada pela técnica subtrativa. 0 arranjo das guitarras também apresenta a guitarra left como referencial métrico, enquanto a guitarra right ${ }^{18}$ gera o processo subtrativo:

17 Ver figuras 3 e 4. Ou seja, não há a aceleração, como ocorre em Piano Phase (1967).

18 Cabe mencionar desde já que a organização no arranjo das guitarras ocorre sempre da mesma maneira: a guitarra left como referencial métrico, inalterado, enquanto a guitarra right atua defasando os padrões motívicos. 


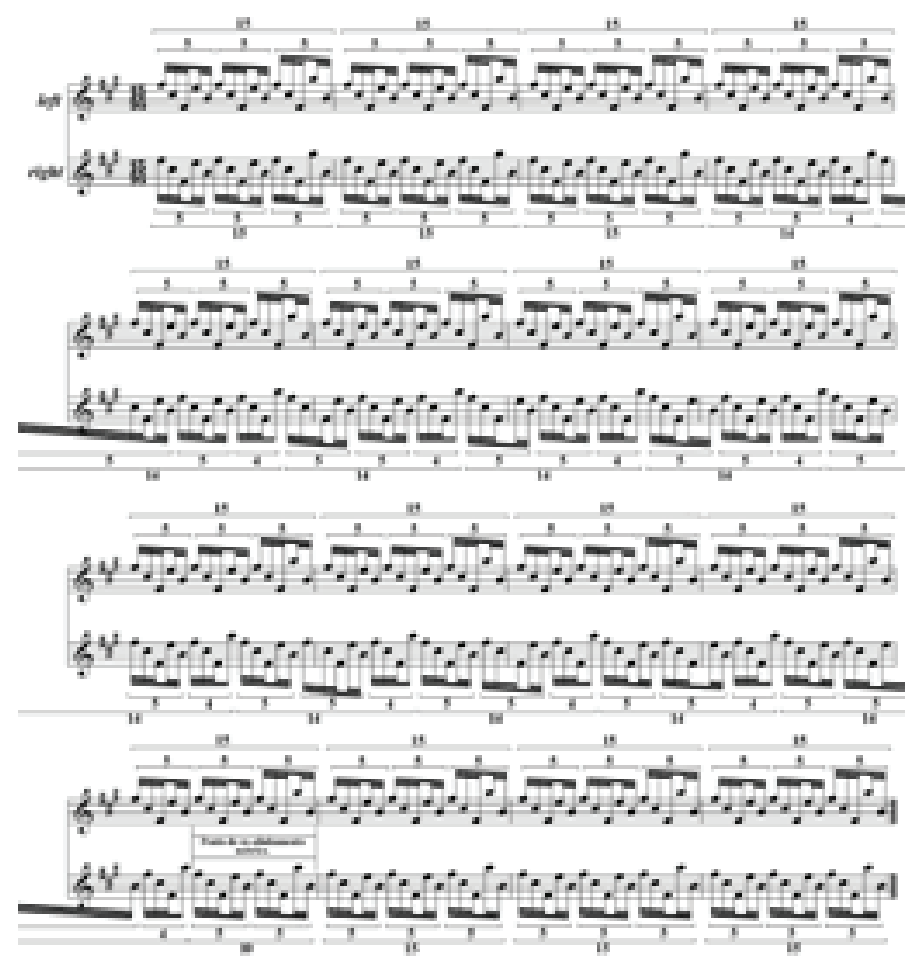

Figura 10 - Seção C.

A similaridade com a metodologia empregada na Seção $A^{\prime}$ também diz respeito ao número de repetições do padrão motívico $15(5[3+2]+5[3+2]+5[3+2])^{19}: 16$ vezes.

0 gráfico abaixo demonstra de forma mais detalhada o processo de defasagem da Seção C. Chama atenção o fato de que este processo é gerado através das duas últimas repetições do padrão métrico $5(3+2)$. Ao invés de manter o deslocamento até a sua finalização no primeiro segmento, houve uma acomodação da guitarra right (último sistema) a fim de restabelecer a sincronia métrica do mesmo padrão em ambas guitarras:

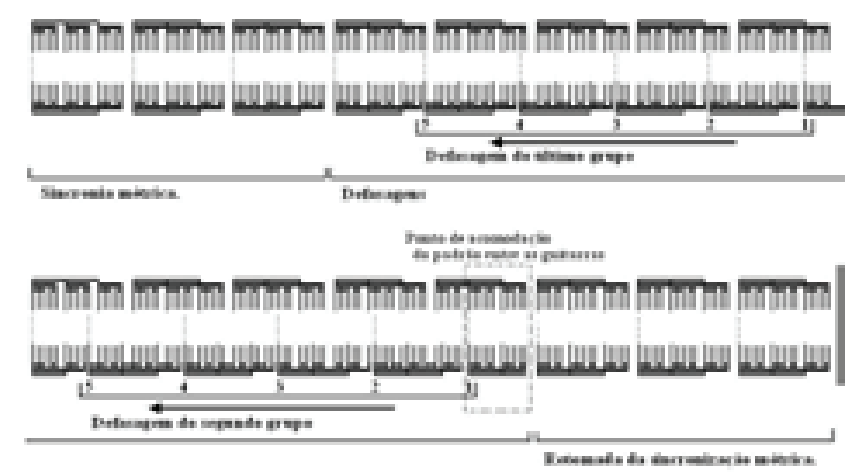

Figura 11 - Estrutura métrica da Seção C.

19 A articulação deste padrão não sugere nenhuma quebra com a relação métrica descrita. Porém, quando variado na Seção C", a articulação se torna mais ambígua. 
A Seção C' constitui-se como uma transposição direta do mesmo padrão da Seção C: uma 5 š justa acima de Fá\# menor (Dó menor). Além disso, a organização do arranjo das guitarras é o mesmo, assim como o número de repetições do mesmo padrão 15 $(5[3+2]+5[3+2]+5[3+2])$ realizado pela guitarra left. A diferença na estruturação fica por conta da localização dos pontos de sincronização métrica. Enquanto na Seção C a estruturação apresenta-se como $16(3+10+3)^{20}$, na Seção $C^{\prime}$ ocorre $16(1+10+5)$ :

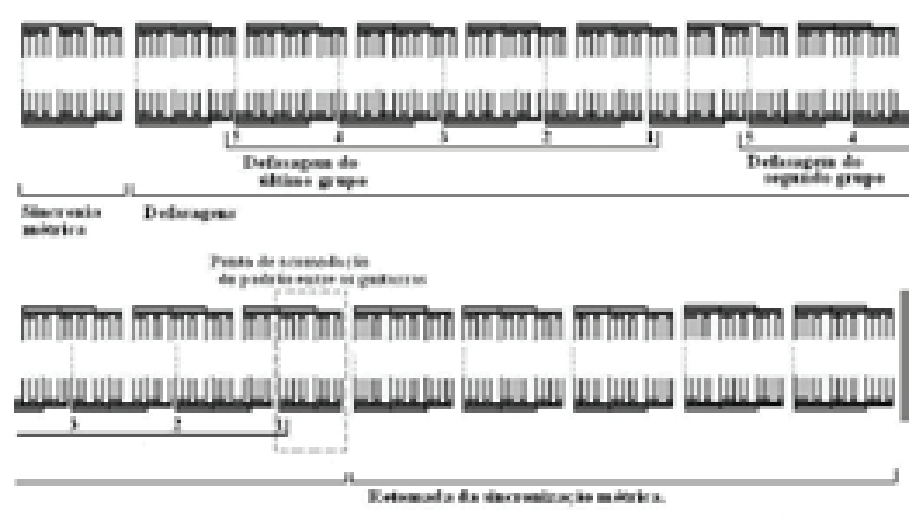

Figura 12 - Estrutura métrica da Seção $C^{\prime}$.

A Seção C" apresenta o mesmo método encontrado em C'. A diferença reside no fato de que $C^{\prime \prime}$ se constitui através da variação do padrão motívico apresentado nas Seções C e C'. Enquanto nestas o padrão referencial é $15(5[3+2]+5[3+2]+5$ $[3+2])$, em C" ele é modificado para $12(5[3+2]+3+4[2+2])^{21}$ :

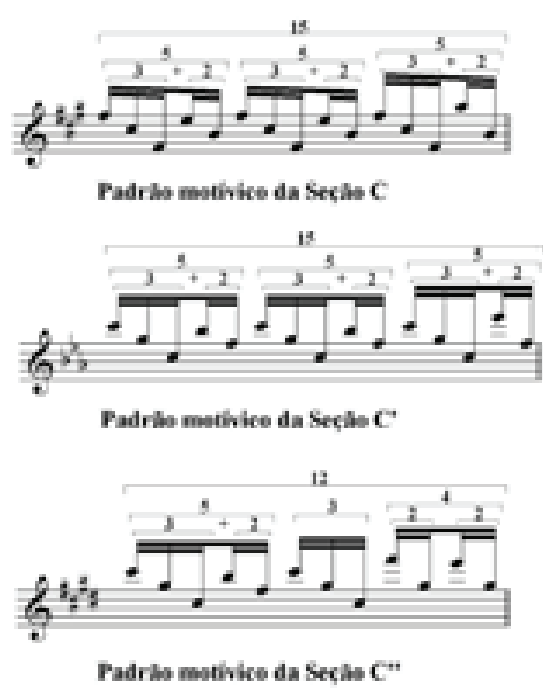

Figura 13 - Comparação entre os padrões motívicos das seções C, C' e C".

200 numeral fora dos parênteses representa o número de repetições do padrão pela guitarra left (referencial métrico); os números dentro dos parênteses representam respectivamente ponto de sincronia métrica, ponto de defasagem e ponto de sincronia métrica.

21 Este padrão motívico pode ser articulado através de outras formas. Porém, na abordagem aqui presente, considera-se a relação destacada. 
Além disso, é uma transposição direta do mesmo padrão de C menor para C\# menor e a defasagem inicia já no primeiro segmento. Sua estruturação é 27 $(11+1+11+4)^{22}$ :

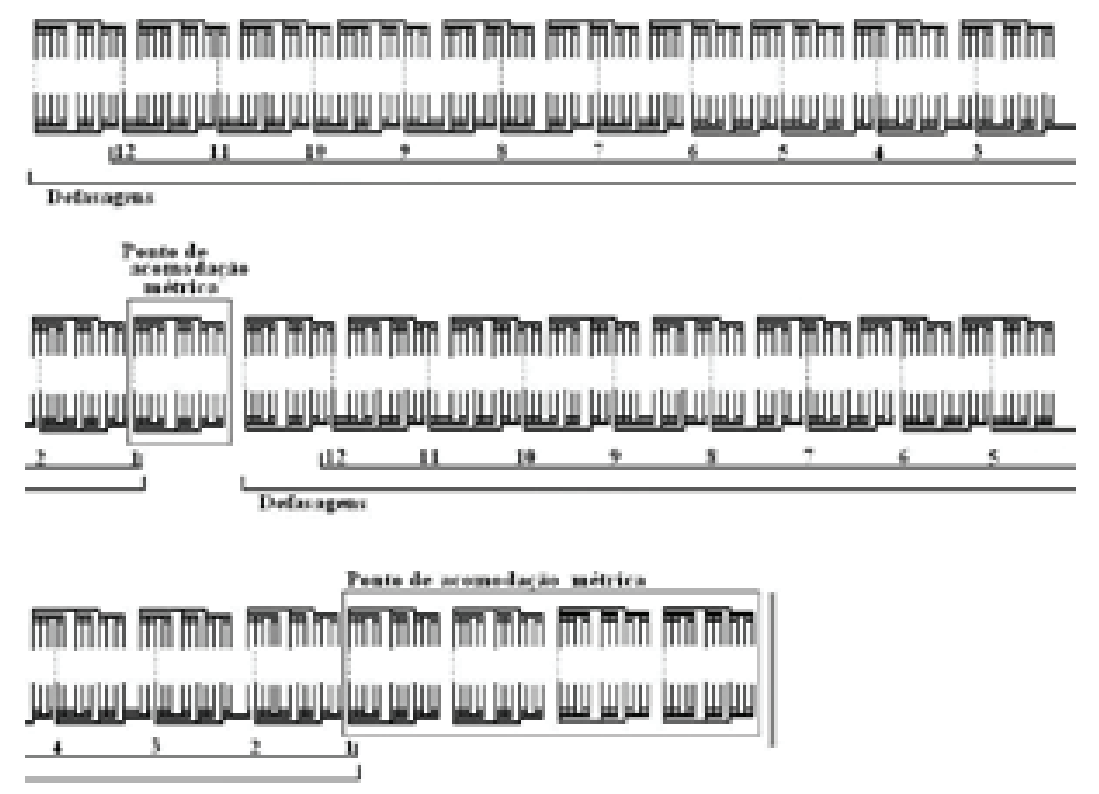

Figura 14 - Estrutura métrica da Seção C".

Por sua vez, a Seção C'" nada mais é do que uma transposição ascendente direta do mesmo padrão motívico $12(5[3+2]+3+4$ [2+2]) da Seção C" (Dó \# menor) para Mi menor. A diferença reside na estruturação métrica. Enquanto C" constitui-se como $27(11+1+11+4)$, em C'", temos $15(11+4)$, ou seja, uma repetição da estruturação dos dois últimos segmentos de C".

Para finalizar, a Seção C'"' constitui-se como um desdobramento da Seção C: apresentam o mesmo procedimento de acomodação $0^{23}$ entre as guitarras para restabelecer sincronia métrica do mesmo padrão. A variação fica por conta da maneira como a Seção C'"' está estruturada (Seção C: $16(3+10+3)^{24}$; Seção C'"': $\left.12(1+7+4)^{25}\right)$ e pelo fato de estar uma oitava acima em relação à Seção C:

220 numeral fora dos parênteses representa o número de repetições do padrão pela guitarra left (referencial métrico); os números dentro dos parênteses representam respectivamente ponto de defasagem, ponto de sincronia métrica, ponto de defasagem e ponto de sincronia métrica.

23 Ver o ponto de acomodação na Seção C na figura 12.

240 numeral fora dos parênteses representa o número de repetições do padrão pela guitarra left (referencial métrico); os números dentro dos parênteses representam respectivamente ponto de sincronia métrica, ponto de defasagem e ponto de sincronia métrica.

250 numeral fora dos parênteses representa o número de repetições do padrão pela guitarra left (referencial métrico); os números dentro dos parênteses representam respectivamente ponto de sincronia métrica, ponto de defasagem e ponto de sincronia métrica. 

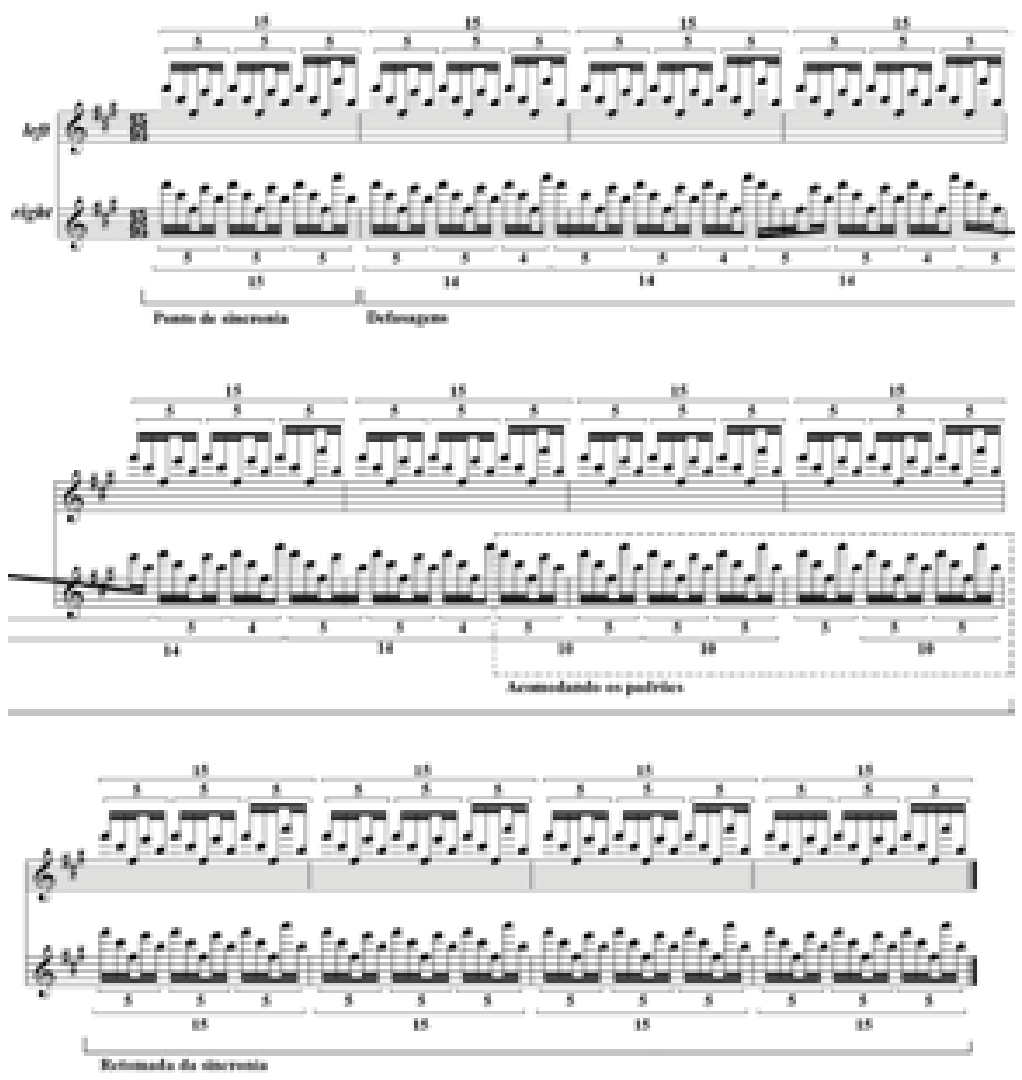

Figura 15 - Superfície da Seção $C^{\prime \prime \prime \prime}$.

\section{Considerações finais}

Acredita-se que este artigo, embora constituindo-se como uma pequena amostra, contribui para a pesquisa em música popular no sentido de que considera uma série de aspectos que possam estar envolvidos em um determinado gênero ou estilo musical. Uma análise que considere tanto aspectos culturais, musicais, bem como estruturais, contribui para uma maior compreensão de como a composição é abordada em vários âmbitos artísticos.

o breve tópico sobre o Rock Progressivo colocado no início de nosso texto, traz uma idéia geral de como seu contexto envolve uma série de elementos oriundos de outros gêneros e tradições musicais. Seu caráter eclético já nos traz uma visão dos problemas envolvidos e da quantidade de aspectos a serem abordados em termos de investigação musical.

No entanto, o Rock Progressivo não surgiu por si só, mas sim, como produto de um contexto muito maior, que abarcou também as iniciativas dos compositores fundadores do próprio minimalismo. Ambos gêneros são contemporâneos de uma série de valores culturais vigentes à época. 0 grupo King Crimson, inserido neste 
contexto, não deixaria de ser influenciado por estes valores. Este ambiente cultural multi-facetado, bem como as iniciativas próprias neste sentido, proporcionaram então, a convergência de vários elementos de diversas tradições musicais em um determinado gênero.

A manifestação dos processos minimalistas analisados na música Discipline, mostram uma pequena parte dos vários aspectos musicais envolvidos. Além disso, as próprias análises se constituem como um fator importante, na medida em que mostram como tais processos foram apreendidos e estruturados por este grupo. A metodologia geral empregada foi a de estabelecer claramente o processo de defasagem através da técnica subtrativa, o que a nosso ver, se constitui como uma importante consideração. Na medida em que observam-se tais aspectos de estruturação, pode-se dizer que no caso da faixa Discipline, e mais especificamente no arranjo das guitarras, estas técnicas minimalistas inspiraram uma parte do processo de composição. 


\section{Referências Bibliográficas}

> BEARD, David; GLOAG, Kenneth. Musicology: the Key concepts. Routledge: New York, 2005.

> CERV0, Dimitri. 0 Minimalismo e suas técnicas composicionais. PER MUSI, 11, 2005, p.44-59.

$>$ Post-Minimalism: A Valid Terminology?. ICTUS, V.1, 1999, p.37-51.

> COVACH, John. King Crimson. In: New Grove Dictionary of Music and Musicians. V.13. New York: Oxford Press, Inc. 2001, pp.609-610.

> GRIFFITHS, Paul. A música moderna: uma história concisa e ilustrada de Debusy a Boulez. Jorge Zahar Editor: Rio de Janeiro, 1987.

> KEELING, Andrew. Musical Guide to In the Court of the Crimson King. Smashwords: Los Gatos, CA, 2010.

> MACAN, Edward. Rocking the Classics: English Progressive Rock at the Counterculture. Oxford University Press: New York, 1997.

> POTTER, Keith. Minimalism. In: New Grove Dictionary of Music and Musicians. http://www.grovemusic.com, 2001.

> SHUKER, Roy. Popular Music: the Key concepts. 2ed. Routledge: New York, 2005.

> TAMM, Eric Alexander. Robert Fripp: from Crimson King to Crafty Master. Faber a Faber: Londres, 1990.

Daniel Ribeiro Medeiros, mestre em Teoria e Criação pela UFPR drmedeiros25@yahoo.com.br 